\title{
Numerical Simulation on the Partition of Gas-Rich Region in Overlying Strata
}

\author{
G. Wang ${ }^{1,2}$, L. L. Sun ${ }^{1,2, *}$ and H. Y. $Q u^{3}$ \\ ${ }^{1}$ State Key Laboratory of Ministry of Mining Disaster Prevention and Control, Shandong University of Science and Technology, \\ Qingdao, 266590- China \\ ${ }^{2}$ College of Resources and Environmental Engineering, Shandong University of Science and Technology, Qingdao, 266590- China \\ ${ }^{3}$ Colorado School of Mines, Colorado, 80402-United States
}

Received 3 December 2013; Accepted 3 March 2014

\begin{abstract}
In the background of Kongzhuang coal mine 7433 working face, theoretical analysis and numerical simulation are adopted. The partition method of gas-rich region in overlying strata based on the key stratum is proposed. Overlying stratas are divided into low concentration and easy for gas drainage area, high concentration and easy for drainage area, primary stress zone according to the control action of key stratum in overlying stratas. The numerical simulation shows that fissure development range is gradually scaling up , and the development range of bed separated fissures and vertical fissures extend to the second inferior key stratum step-by-step with the working face moving forward The fissure development range stabilizes as the roof periodic motion and moves forward with the working face moving forward. Compared to traditional empirical formula calculation result, the top boundary of high concentration and easy for drainage area according to this method is higher than the calculated limit of water flowing fractured zone. The design of gas drainage can be more accurately guided. Better gas drainage effect is obtained by the design of gas drainage in 7433 working face which is based on this method and the numerical simulation result. The effectiveness and rationality of this method are verified.
\end{abstract}

Keywords: Pressure Relief Gas, Key Stratum, Gas-rich Region, Numerical Simulation

\section{Introduction}

Coal mine gas is one of the major disasters that threaten safety production in coal mine, which not only limits the production increase, but also greatly increases the cost. The drainage of pressure relief gas in gob will overcome the problem of low permeability of coal seam in most coal mines in China and lower the drainage cost [1]. In recent years, mining-induced fracture fields and seepage field of gas are extensively studied by scholars aiming at pressure relief gas in goaf in China.. Research achievements includes evolution of permeability, gas-solid coupling rules, distribution rule of gas flow field are obtained [2], [3], [4]. However, these research results haven't quantitatively divided different gas concentration regions combined the motion laws of overburden strata.

Gas migration in mining-induced fissure field mainly includes rising and floating effect and diffusion effect [5], [6]. Gas will flow to the drainage holes in form of seepage through fissures under the conditions that drainage measures exist, such as drainage drillings. The whole or partial overlying stratas are controlled by key stratums according to the definition of key stratums, and there are bed separated fissures below them. The bed separated fissures between the key stratums of overlying stratas and thin soft rock stratas is the most developed area [7], [8]. Therefore, the partition of gas-rich region by key stratum is feasible. The UDEC software is used for numerical simulation. The partition of gas-rich region of overlying strata based on the key strata is researched by the numerical simulation.

\section{Partition of gas-rich region}

Under the condition of more than one key stratums existing in the overlying stratas of working face, after the judgement of key stratum and the calculation of relief index of stress of key stratums, if the relief index of stress of one key stratum is larger than the critical value, and relief index of stress of the key stratum above is smaller than the critical value or there is no key stratum above, this key stratum can be confirmed as the critical region of gas drainage [9], [10]. High concentration gas can be drained by drainage drillings which are drilled under this critical region. Therefore, the overlying strata can be partitioned to "low concentration and easy for gas drainage area", "high concentration and easy for gas drainage area", and "primary stress zone" by key stratums, as shown in figure 1. The critical key stratum is the limit of "high concentration and easy for gas drainage area" and "primary stress zone".

\footnotetext{
*E-mail address: sunlukdck@163.com

ISSN: 1791-2377 @ 2014 Kavala Institute of Technology. All rights reserved.
} 


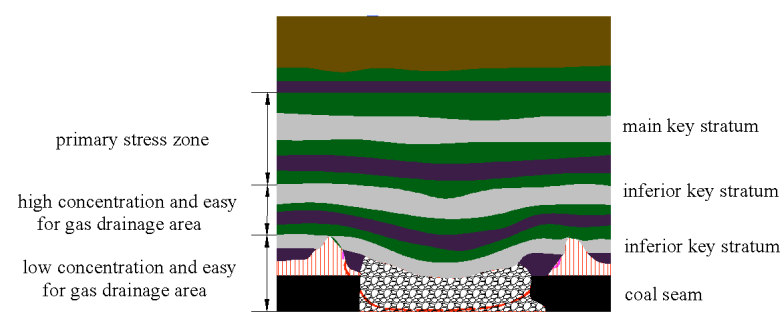

Fig. 1 Schematic diagram of gas-rich region

It is the "low concentration and easy for gas drainage area" from the bottom up. There are many vertical fissures with high porosity and permeability in this area, and the gas concentration is low. Gas in the "high concentration and easy for gas drainage area" seeps mainly by the system of mining-induced fissures. There is a large amount of accumulative high concentration gas in the bed separated fissures. The top of overlying stratas is the "primary stress zone". Effective gas drainage can not be used in this area because it has less affected by mining with low permeability and no obvious mining-induced fissure.

\section{Geological condition of testing working face}

7433 fully mechanized caving face is the first mining face of IV 1 mining area locating in the upside of its eastern part. The north of 7433 working face is $-940 \mathrm{~m}$ contour line and the south is $-880 \mathrm{~m}$ contour line, and it reachs Fc11 fault in the east and IV 1 return airflow dip in the west. The ground elevation and the elevation of 7433 working face are +32.59 $\mathrm{m}$ and -946 -836 $\mathrm{m}$. The design strike length is about 1400 $\mathrm{m}$, the dip length is $134.25 \mathrm{~m}$, the thickness of coal seam is $4.30 \sim 5.49 \mathrm{~m}$ which is $4.60 \mathrm{~m}$ by average, the mining height and caving height are $2.40 \mathrm{~m}$ and $2.40 \mathrm{~m}$, the mining and caving ratio is $1: 1$, the coal seam dip angle of the working face is $22 \sim 28^{\circ}$ which is $25^{\circ}$ by average, the mining rate is $85 \%$. The gas emission is large and gas transfinite phenomenon occurred during the period of roadway excavation. This threatens the safety production of this working face seriously.

\section{Numerical simulation}

\subsection{Establishment of model and the determination of parameters}

The model is made by Kongzhuang Coal mine 7433 working face and its overlying stratas in this simulation. The mechanical parameters of strata and joint surface are showed in table 1 .

After the calculation, the distance between the first inferior key stratum and coal seam roof is $22.85 \mathrm{~m}$, the distance between the second inferior key stratum and the first inferior key stratum is $22.08 \mathrm{~m}$ and the distance between the main key stratum and the second inferior key stratum is $35.39 \mathrm{~m}$. The numerical calculation simulation along the working face is established in order to analyse the motion law of overlying stratas along the working face, as shown in figure 2. The height, length and mining depth of working face of this model are separately $100 \mathrm{~m}, 200 \mathrm{~m}$, and $900 \mathrm{~m}$. The gravity stress of the overlying strata is applied on the upper boundary condition of the model. Basic roof and immediate roof are set below the coal seam according to the actual situation. The distance between the left mining boundary and the left model boundary is $50 \mathrm{~m}$.

Tab.1. Parameters of coal-rock and joint surface.

\begin{tabular}{|c|c|c|c|c|}
\hline $\begin{array}{c}\text { Strata } \\
/ \text { Coal Seam } \\
\end{array}$ & Coal & Mudstone & $\begin{array}{c}\text { Sandy } \\
\text { mudstone }\end{array}$ & Sandstone \\
\hline Density & 1.35 & 2.6 & 2.8 & 2.9 \\
\hline $\begin{array}{c}\text { Bulk } \\
\text { modulus }\end{array}$ & 4.5 & 8.7 & 11 & 27 \\
\hline $\begin{array}{l}\text { Shear } \\
\text { modulus }\end{array}$ & 2.5 & 5 & 5.5 & 15 \\
\hline $\begin{array}{l}\text { Internal } \\
\text { friction } \\
\text { angle }\end{array}$ & 18 & 34 & 38 & 45 \\
\hline Cohesion & 1.5 & 28 & 27 & 30 \\
\hline $\begin{array}{l}\text { Tensile } \\
\text { strength }\end{array}$ & 1.5 & 12 & 20 & 22 \\
\hline $\begin{array}{l}\text { Normal } \\
\text { stiffness }\end{array}$ & 3 & 5 & 12 & 20 \\
\hline $\begin{array}{l}\text { Tangential } \\
\text { stiffness }\end{array}$ & 0.3 & 2 & 8 & 16 \\
\hline $\begin{array}{l}\text { Bond } \\
\text { force }\end{array}$ & 0 & 0 & 0 & 0 \\
\hline $\begin{array}{l}\text { Friction } \\
\text { angle }\end{array}$ & 28 & 28 & 35 & 39 \\
\hline $\begin{array}{l}\text { Tensile } \\
\text { strength }\end{array}$ & 0 & 0 & 0 & 0 \\
\hline
\end{tabular}

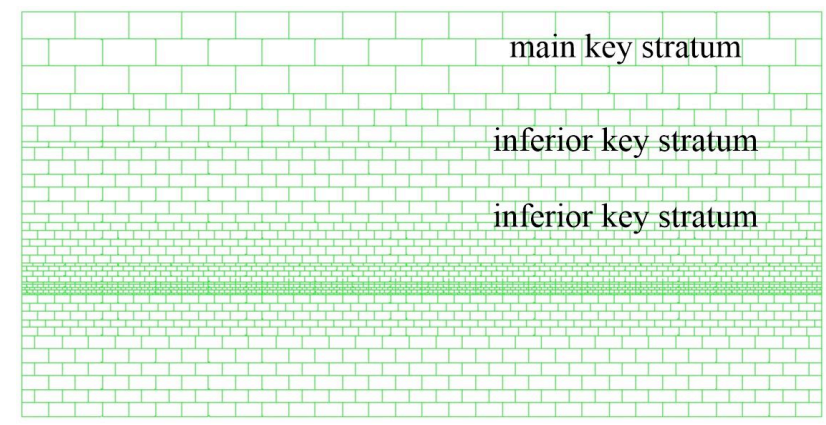

Fig. 2 Numerical simulation calculation model

\subsection{Determination of initial stress and boundary condition}

According to the existing related research, the mechanics of deformation of sedimentary rocks can be described by plastoelasticity model. The Mohr-Coulomb yield criterion is chosen and coulomb sliding model contacting surface is adopted by joint material model [11], [12].

Horizontal stress is calculated by side pressure coefficient $\mathrm{k}$ through formula (1) [13].

$$
k=\mu /(1-\mu)
$$

\section{Where, $\mu$ is poisson ratio.} [14]:

The boundary conditions of the model are set as follows

The upper boundary condition: The load of upper coal seam is simplified as uniformly distributed load. The upper boundary condition is the stress boundary condition, meaning $q=\sum \gamma h=22.5 \mathrm{MPa}$;

The lower boundary condition: The lower boundary condition of the model is simplified as the boundary condition of displacement. The y direction is set to a fixed 
hinge bearing. The displacement can be made on the $\mathrm{x}$ direction.

The boundary condition of both sides: The lower boundary condition of the model is simplified as the boundary condition of displacement. The $\mathrm{x}$ direction is set to a fixed hinge bearing. The displacement can be made on the y direction.

\subsection{Results and analysis of numerical simulation}

With the proceeding of working face, the development degree of fissures is indicated in red. The motion of overlying stratas and fissures development evolution in working face are showed by figures $3 \sim 7$ while excavating at $15 \mathrm{~m}, 30 \mathrm{~m}, 60 \mathrm{~m}, 90 \mathrm{~m}$, and $130 \mathrm{~m}$.

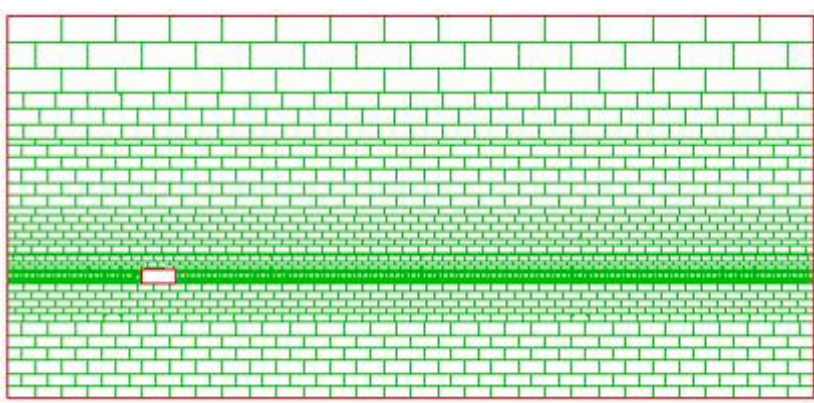

Fig. 3 Overburden stratas movement and fissures development while excavating at $10 \mathrm{~m}$

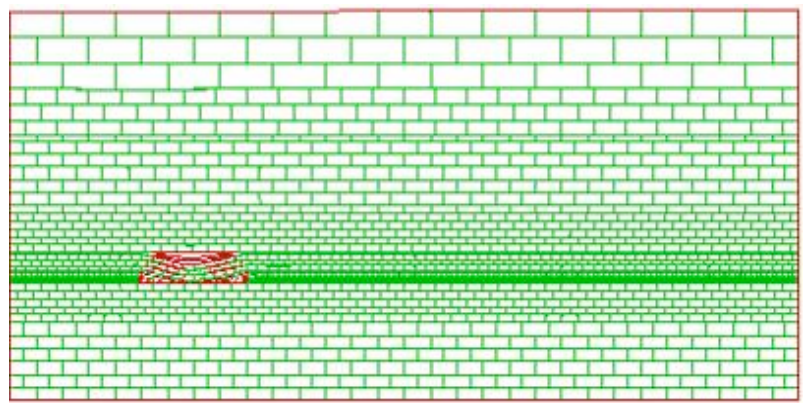

Fig. 4 Overburden stratas movement and fissures development while excavating at $30 \mathrm{~m}$

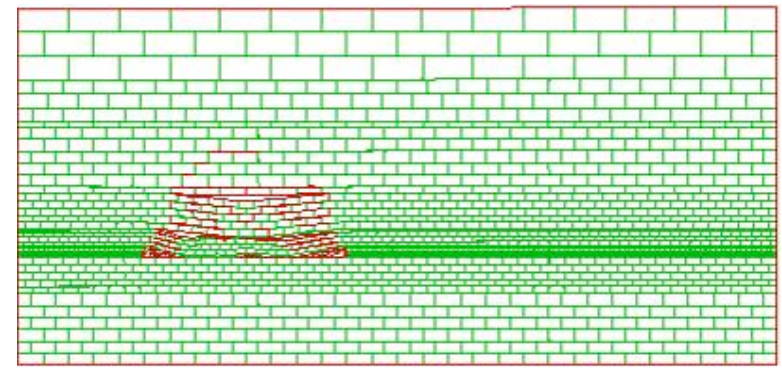

Fig. 5 Overburden stratas movement and fissures development while excavating at $60 \mathrm{~m}$

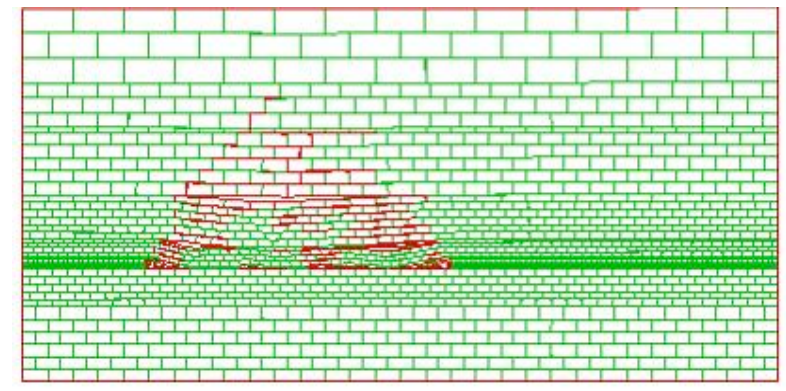

Fig. 6 Overburden stratas movement and fissures development while excavating at $90 \mathrm{~m}$

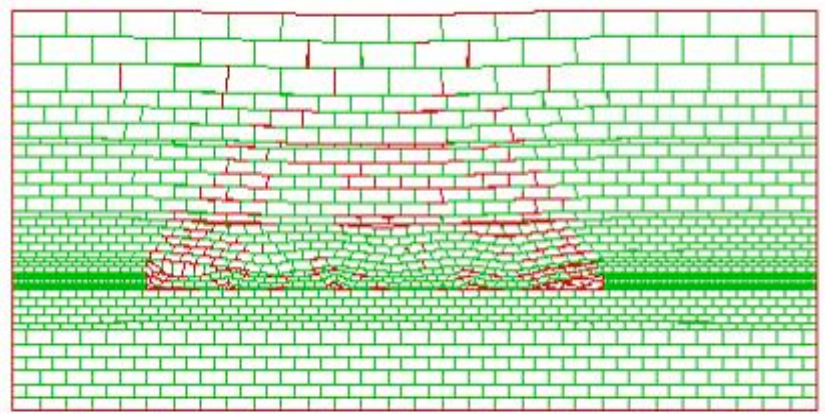

Fig. 7 Overburden stratas movement and fissures development while excavating at $130 \mathrm{~m}$

The working face which is mined from the cutting hole and the overlying stratas maintains integrity with no obvious mining-induced fissure and break while excavating at $10 \mathrm{~m}$. With the working face's moving forward, the length of hanging roof increases and bending deformation appears in overlying stratas because of the self-gravity while excavating at $30 \mathrm{~m}$. The immediate roof falls and first weighting occurs, and fissures are distribute among the range of $4 \sim 16 \mathrm{~m}$ in overlying stratas, and this is consistent with mineral pressure observation result. The migration range increases with mining and there are shear failures in both front and back of the goaf, and the tensile failure fissures appear. While excavating at $60 \mathrm{~m}$, affected by the mining-induced, the inferior key stratum moves under the combined action of principal stress and shear stress. The first weighting of main roof occurs while the immediate roof falls. There are bed separated fissures and vertical fissures in the top of caving zone. With the working face's moving forward, the development range of bed separated fissures and vertical fissures extend to the second inferior key stratum step-by-step. The overlying stratas present the periodic motion feature. The range of fissures will gradually steady and move forward.

The partition of gas-rich region based on numerical simulation is shown in figure 8 . According to the development and distribution of fissures, the overlying stratas can be partitioned in to "low concentration and easy for gas drainage area", "high concentration and easy for gas drainage area" and "primary stress zone" from the bottom up. This is consistent with the consequence made by theoretical analysis.

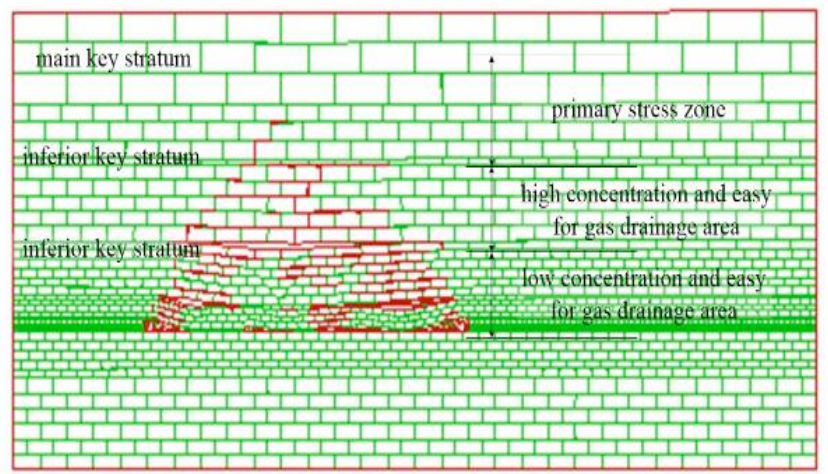

Fig. 8 Partition of gas-rich region basing on the result of numerical simulation 


\subsection{Empirical formula calculation of fissures development range}

According to the existing motion laws of overburden strata and gas delivery laws, the height of drainage drillings $H_{z}$ should be in the range of fractured zone, which is :

$H_{m}<H_{z}<H_{l}$

Where, $H_{m}$ is the height of caving zone, $H_{l}$ is the height of fractured zone.

The height of caving zone and fractured zone are calculated by the empirical formula below.

$$
H_{m}=\frac{M}{(k-1) \cos \alpha}
$$

Where, $M$ is the mining height, $4.8 \mathrm{~m} ; k$ is the average coefficient of bulk increase of caving rocks, 1.3; $\alpha$ is the coal seam dip angle, $25^{\circ}$.

$$
H_{l}=\frac{100 M}{a M+b} \pm c
$$

Where, $a, b, c$ are undetermined constants which can be chosen from the designing standard for coal mine, as shown in table 2.

Tab.2. Values of undetermined constants.

\begin{tabular}{c|c|c|c}
\hline rock formation property & $\mathrm{a}$ & $\mathrm{b}$ & $\mathrm{c}$ \\
\hline hard & 1.2 & 2.0 & 8.9 \\
mid-hard & 1.6 & 3.6 & 5.6 \\
soft & 3.1 & 5.0 & 4.0 \\
extremely-soft & 5.0 & 8.0 & 3.0 \\
\hline
\end{tabular}

According to the geological data of 7433 working face, the overlying stratas are mid-hard. The height of caving zone and fractured zone are separately $17.65 \mathrm{~m}$ and $36.95 \sim 42.55$ $\mathrm{m}$, calculated by formula (2), (3) and (4). Combining the definition of key stratum and the numerical simulation result, the height of the "low concentration and easy for gas drainage area" is $27.45 \mathrm{~m}$, the height of the "high concentration and easy for gas drainage area" is $49.53 \mathrm{~m}$. Because the bed separated fissures under key stratum is more developed, the height of the "high concentration and easy for gas drainage area" is $49.53 \mathrm{~m}$ which is higher than the range of fractured zone that calculated by the empirical formula. This method can make more accurate guidance of the design of gas drainage.

\subsection{Engineering application effect}

According to the definition of key stratum and the numerical simulation result, the design of gas drainage for 7433 working face has been made. The comparison of gas concentration of top corner and return current with no measures and under gas drainage are shown in figure 9 and figure 10 . The gas concentration falls by $66.7 \%$ and $53.5 \%$ in top corner and return current. The flow of drainage drillings is lower than other gas control measures, this can eliminate the gas threat and alleviate the air leak quantity and mine fire threat at the same time.

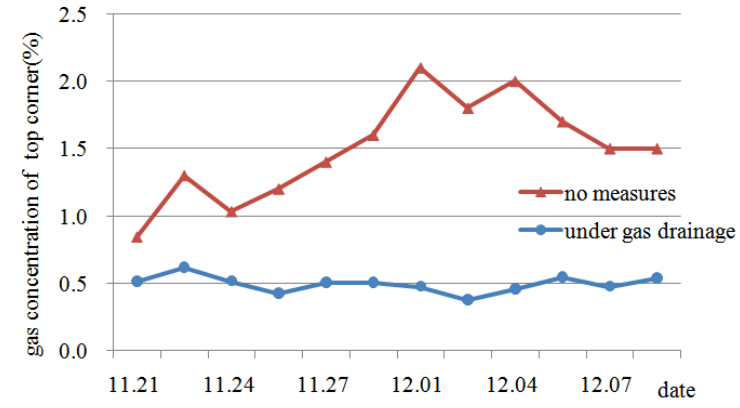

Fig. 9 The measurement results of gas consistence in top corner

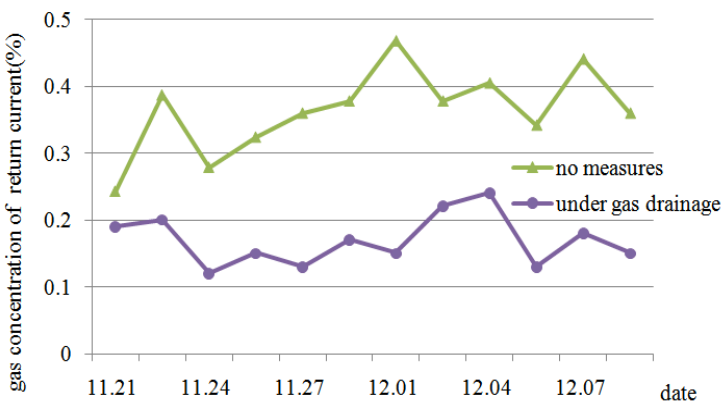

Fig. 10 The measurement results of gas consistence in return current

\section{Conclusions}

Under the condition of more than one key stratums existing in the overlying stratas of working face, the overlying stratas can be partitioned to "low concentration and easy for gas drainage area", "high concentration and easy for gas drainage area" and "primary stress zone" by key stratums. Gas in the "high concentration and easy for gas drainage area" seeps mainly by the system of mining-induced fissures. There is a large amount of accumulative high concentration gas in the bed separated fissures, so it is the target area of gas drainage.

The numerical simulation model of 7433 working face in Kongzhuang Coal mine is established. The result of numerical simulation shows that with the working face's moving forward, the development range of bed separated fissures and vertical fissures extend to the second inferior key stratum step-by-step. The range of fissures will gradually steady and move forward. The height of the "high concentration and easy for gas drainage area" worked out by this method is higher than the range of fractured zone that calculated by the empirical formula. This method can make more accurate guidance of the design of gas drainage.

According to the definition of key stratum and the numerical simulation result, the gas drainage for 7433 working face has been designed. The gas concentration falls by $66.7 \%$ and $53.5 \%$ in top corner and return current.

\section{Acknowledgements}

The authors would like to acknowledge the support of National Natural Science Foundation Project (51304128), Scientific Research Foundation of Shandong University of Science and Technology for Recruited Talents (2013RCJJ049), Open Project of State Key Laboratory 
Breeding Base for Mining Disaster Prevention and Control(Shandong University of Science and Technology)(MDPC2012KF10), China Postdoctoral Science Foundation (2013M541942), Shandong Provincial Natural
Science Foundation, China (ZR2013EEQ015) and Specialized Research Fund for the Doctoral Program of Higher Education (20133718120013).

\section{References}

1. Wu R.-L., Xu J.-L., K.X., Shi C.-T., Luo B.-L., Hu Y.-M, Li Y.-K., 2010. "Gas pressure relief rule of overlying coal seam induced by fully mechanized top coal caving in long working face", Journal of Mining \& Safety Engineering 21 (7), 2010,pp. 8-12+18.

2. Wang Y.-G., Li H.-Y., Qi Q.-X., Peng Y.-W, Li C.-R., Deng Z.-G., "The evolution of permeability and gas extraction technology in mining coal seam", Journal of China Coal Society 35 (3), 2010, pp. 406-410.

3. Wang L., Cheng Y.P., Jiang J.Y., Guo P.K., Wang L.G., Yang Y., "The coupling laws between fissure field and gas flow field under an extremely thick igneous rock", Journal of China Coal Society 35 (8), 2010, pp. 1287-1291.

4. Dong G.-F., Hu Q.-T., Wang Z., Shi B.-M., "Study on distribution of gas flow fields in working face under the condition of mining", Journal of Mining \& Safety Engineering 29 (4), 2012, pp. 581-585.

5. Guo Y.-S., Lin B.-Q., Wu C.-S., "Coupling relation of crack evolvement in surrounding rocks with the storage and migration of mining induced releasing gas", Journal of Mining \& Safety Engineering 24 (4), 2007, pp. 414-417.

6. Sun L.-L., "Study on oriented control technology of gas rich region in working face uder mining", Qingdao: Shandong University of Science and Technology, 2013.
7. Qian M.-G., Miao X.-X., "Theoretical study of key stratum in ground control", Journal of China Coal Society 21 ( 3) 1996, pp. 225-230.

8. Qian M.-G. Shi P.-W., "Mining pressure and strata control", Xuzhou: China University of Mining and Technology Press, 2003.

9. Wu R.-L., "Sudy on the sope of the "tree znes" of as pessure rlief and etraction in coal seam group mining", Xuzhou: China University of Mining and Technology, 2011.

10. Qu Q.-D., "Study and application and on the theory of the "Three Zones" of gas pressure relief in overlying strata", Xuzhou: China University of Mining and Technology, 2010.

11. Shi B.-M., Liu Z.-G., "Numerical simulation of the upper coal and rock deformation characteristic caused bym ining protecting stratum", Journal of China Coal Society 33 (1), 2008, pp. 17-22.

12. Li Z., Wang H.-P., Li S.-C., Wang Q., Li W.-T., Jiang B., "Study on the fissure evolution law of overlying strata during mining", Journal of Shandong University 41 (3), 2011, pp. 142-147.

13. Ma Z.-F., Yu Q.-X., Chen X.-X., "Numerical value simulation on preventing outburst function with hydraulic stress pre-release", China Safety Science Journal 16 (10), 2006, pp. 27-31.

14. Feng G.-R., "Study on the theory and its application of upward mining of left-over coal", Taiyuan: Taiyuan University of Technology, 2009. 